\title{
Surface localization of the Er-related optical active centers in Er doped zinc oxide films
}

\author{
Fahad Azad, ${ }^{1}$ Caiqin Luo, ${ }^{1}$ Shichen Su, ${ }^{1}$ Muhammad Younas, ${ }^{2}$ Waqar Azeem, ${ }^{1}$ \\ Andrej Kuznetsov, ${ }^{3}$ Alexander Azarov, ${ }^{3}$ Kaimin Shih, ${ }^{4}$ Changzhong Liao, ${ }^{4}$ \\ Asghari Maqsood, ${ }^{5}$ and Francis Chi-Chung Ling ${ }^{1, a)}$ \\ ${ }^{1}$ Department of Physics, The University of Hong Kong, Pokfulam Road, Hong Kong, China \\ ${ }^{2}$ Electronic and Magnetic Materials Group (EMMG), PD, PINSTECH, PO Nilore, Islamabad, Pakistan \\ ${ }^{3}$ Department of Physics, Oslo University, Oslo, Norway \\ ${ }^{4}$ Department of Civil Engineering, The University of Hong Kong, Pokfulam Road, Hong Kong, \\ People's Republic of China \\ ${ }^{5}$ Nano-Scale Physics Laboratory, Department of Physics, Air University, PAF Complex, \\ E-9, Islamabad, Pakistan
}

(Received 28 February 2017; accepted 2 June 2017; published online 16 June 2017)

Er-doped $\mathrm{ZnO}$ films were grown on c-plane sapphire by employing the pulsed laser deposition method. In accordance with the previously reported literature studies, post-growth annealing was required to activate the optical emission originated from the intra-shell transitions of the Er atoms. Importantly, the present systematic studies revealed that the thermal activation of the optical activity is due to the atomistic rearrangements occurring only in the vicinity of the film surface. The processes exhibit a distinct signature of changing oxygen coordination with the Er atom, as observed by the x-ray photoemission study. Published by AIP Publishing. [http://dx.doi.org/10.1063/1.4986234]

\section{INTRODUCTION}

Erbium doped semiconductors are important for optoelectronic devices ${ }^{1-3}$ because of their intra- $4 \mathrm{f}$ shell transition related emission at $1.54 \mu \mathrm{m}$ and used in telecommunication technology for their maximum transparency in $\mathrm{SiO}_{2}$-based optical fibers. Extensive luminescence studies have been carried out in narrow band-gap semiconductors (mainly $\mathrm{Si}$ ) doped with Er. ${ }^{4-8}$ Although strong luminescence was observed in Er-doped $\mathrm{Si}$ at low temperatures, thermal quenching of $\mathrm{Er}$ luminescence $^{9}$ (due to non-radiative energy back transfer pro$\operatorname{cesses}^{10}$ ) limits its use in practical applications. Fortunately, this Er luminescence quenching decreases with the increasing band gap of the semiconductor host, and $\mathrm{ZnO}$ being a wide band gap semiconductor is thus considered as an appropriate host for the Er dopant. ${ }^{11}$ Indeed, studies of fabricating Erdoped $\mathrm{ZnO}$ (EZO) films by various deposition techniques ${ }^{12-16}$ showed that Er-doped $\mathrm{ZnO}$ can be used in laser diodes, light emitting diodes, phosphors for lighting, and optical amplifiers operating at $1.54 \mu \mathrm{m}$ in a wave guide structure. As-grown EZO is usually reported to be optically inactive in intra- $4 \mathrm{f}$ shell transitions, and annealing is needed to create a suitable crystal field around the $\mathrm{Er}$ in the $\mathrm{ZnO}$ lattice for making these transitions feasible. Ishii et al. studied the Er LIII x-ray absorption fine structure (XAFS) spectrum to explore the structural changes that occur during the annealing process in EZO.$^{17}$ The difference in the $\mathrm{k}^{3} \chi$ spectrum of as-ablated and annealed samples was attributed to Er local structure's modification as a result of annealing. The shape of the spectrum of the annealed EZO sample was found to be similar to that of optical active Er:Si, which indicates the pseudo-octahedral Er-O structure (like $\mathrm{Er}: \mathrm{Si}$ ) in the annealed sample. The Fourier transform analysis

a)Email: ccling@hku.hk of the $\mathrm{k}^{3} \chi$ spectra disclosed oxygen to be the first nearest neighbor of $\mathrm{Er}$ in the as-ablated samples and structural distortion due to the pseudo-octahedron in the annealed sample. The back Fourier transformation was performed on Fourier transform $\mathrm{k}^{3} \chi$ spectra, and fitting was done by the photoelectron backscattering theory. The back Fourier transformed spectra and their fitting revealed a $\mathrm{C}_{4 \mathrm{v}}$ structure in annealed EZO samples. In the as-ablated sample, the fitted Er coordination number was found to be $\sim 4.56$ and $\sim 7.64$ for the first and second nearest neighbor, respectively. A model to describe the optical activation of EZO upon annealing was also proposed. It was suggested that in the optically inactive (as-grown) EZO, Er on average occurs in a five-fold coordinatoral configuration with oxygen, and each Er-O bond has a bond-length of $2.217 \AA$. Er bonded with five oxygen atoms is further centred inside an $\mathrm{O}$ cubic structure having one $\mathrm{O}$ atom at each corner of the O-cube. This O-cube was suggested to disturb the crystal field around $\mathrm{Er}$, leading to the distortion in its intra-4f-shell transitions and thus suppressing the optical activity of the as-grown EZO. Annealing facilitated the oxygen atoms surrounding the O-cube to bond with Er, resulting in the formation of a $\mathrm{C}_{4 \mathrm{v}}$ optical active Er center, while the excess of $\mathrm{O}$ atoms (of the initial O-cube) diffuse out into the $\mathrm{ZnO}$ host due to annealing (see Fig. 9 in Ref.17).

In the present work, systematic studies of the Er-doped $\mathrm{ZnO}$ films fabricated by the pulsed laser deposition (PLD) were carried out by employing a comprehensive spectroscopic approach including X-ray diffraction (XRD), secondary ion mass spectroscopy (SIMS), Rutherford backscattering spectroscopy (RBS), Hall effect measurements, optical transmission measurements, photoluminescence (PL) spectroscopy, and X-ray photoelectron spectroscopy (XPS). The results showed that the optical active Er centers stimulated by the thermal annealing only resided on the surface of the film. 


\section{EXPERIMENTAL}

EZO films were grown on c-plane sapphire using a pulsed $\mathrm{KrF}$ excimer laser $(\lambda=248 \mathrm{~nm})$ with a pulse energy of $300 \mathrm{~mJ}$ and a repetition frequency of $2 \mathrm{~Hz}$. The background pressure was $4 \times 10^{-4} \mathrm{~Pa}$. $\mathrm{ZnO}: \mathrm{Er}$ targets with $\mathrm{Er}$ compositions of $0.5 \%, 1 \%$, and $2 \%$ by mass were used for growing the films. By employing XPS, the Er atomic percentage in the $\mathrm{ZnO}$ lattice was found to be $0.53 \%$ and $1.63 \%$ for the films fabricated from the $\mathrm{ZnO}: \mathrm{Er}(1 \%)$ and $\mathrm{ZnO}: \mathrm{Er}$ (2\%) targets, respectively. During the growth, the substrate temperature was kept at $600^{\circ} \mathrm{C}$ and the oxygen pressure was $1.5 \mathrm{~Pa}$ unless otherwise specified. Isochronal $(40 \mathrm{~min})$ postgrowth annealing was performed at 650,750 , and $850^{\circ} \mathrm{C}$ in an argon atmosphere. XRD measurements were performed using a D8 Advance Diffractometer (Bruker AXS) with a Lynxeye detector, operating at $40 \mathrm{kV}$ and $40 \mathrm{~mA}$ with $\mathrm{Cu}$ $\mathrm{K} \alpha$ radiation at room temperature. For the RBS study, $1.6 \mathrm{MeV}{ }^{4} \mathrm{He}^{+}$ions were backscattered into the detectors placed at $165^{\circ}$ relative to the incident beam direction. SIMS measurements were performed using a Cameca IMS $7 \mathrm{f}$ microanalyzer with $10 \mathrm{keV} \mathrm{O}_{2}{ }^{+}$as the primary beam. The intensity-concentration calibration was performed using ion implanted reference samples. Room temperature Hall effect measurements were performed with the Van der Pauw configuration using the Accent HL-5500PC system. The $325 \mathrm{~nm}$ line from the Kimmon $30 \mathrm{~mW} \mathrm{He}-\mathrm{Cd}$ laser was used in the PL measurements for the excitation source. A monochromator (focal length $=500 \mathrm{~mm}$ ), lock-in amplifier, and photomultiplier (PMT) were used for the PL spectrum acquisition. To achieve low temperature, samples were loaded in the Oxford Instrument $(10 \mathrm{~K})$ closed cycle He refrigerator. The hydrogen plasma treatment (HPT) was performed at a power of $150 \mathrm{~W}$ and a pressure of 0.7 Torr at room temperature for $5 \mathrm{~min}$. The XPS measurements were conducted with the $\mathrm{MgK} \alpha$ line using the Kratos Axis Ultra DLS system. The XPS spectrum was taken at the surface and $\sim 20 \mathrm{~nm}$ below the surface of the samples. For the measurement underneath the surface, sputtering was performed by employing Ar ions of energy $2 \mathrm{kV}$ with a $3 \times 3 \mathrm{~mm}$ raster and an extractor current of $100 \mu \mathrm{A}$. The sputtering rate was adjusted in consonance with $\mathrm{SiO}_{2}(0.19 \AA / \mathrm{s})$.

\section{RESULTS AND DISCUSSION}

XRD patterns of the as-grown EZO films grown with different Er contents show only the (002) and (004) diffraction peaks typical for the wurtzite structure, implying a good crystallinity for all the samples (not shown). Figure 1 shows the XRD spectra of $\mathrm{ZnO}$ :Er with Er weight compositions of $0.5 \%, 1 \%$, and $2 \%$ upon annealing at $750{ }^{\circ} \mathrm{C}$, which also exhibits only the $\mathrm{ZnO}(002)$ peak with no peak related to other secondary phases. The c-axis lattice parameters of the $0.5 \%, 1 \%$, and $2 \%$ Er-doped samples were determined to be $5.197 \AA, 5.181 \AA$, and $5.178 \AA$, respectively, revealing a decreasing lattice parameter trend with the increasing $\mathrm{Er}$ concentration. The top right inset in Fig. 1 shows the (002) peak in the XRD spectra of the $\mathrm{ZnO}: \mathrm{Er}(1 \%)$ samples in the as-grown state and after annealing at $750^{\circ} \mathrm{C}$. It is clearly seen that the annealing leads to the increase in the (002)

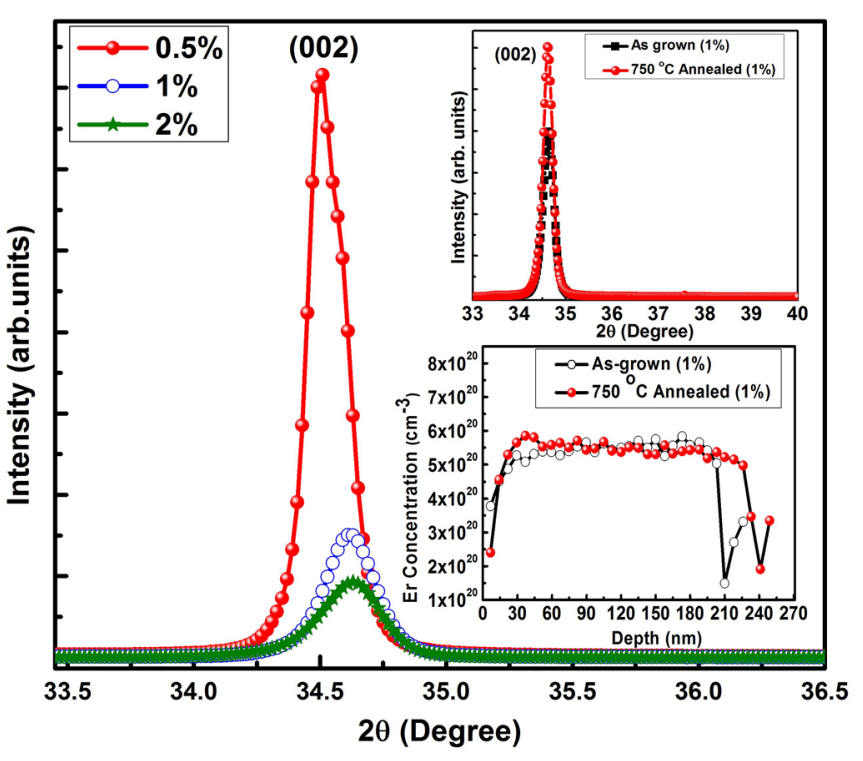

FIG. 1. The (002) peak of $\mathrm{ZnO}$ :Er films grown with different Er compositions after $750{ }^{\circ} \mathrm{C}$ annealing. The insets show (top) comparison of the (002) peak for the as-grown versus the $750^{\circ} \mathrm{C}$ annealed $\mathrm{ZnO}: \mathrm{Er}(1 \%)$ sample; and (bottom) corresponding Er distribution depth profiles.

peak intensity and slightly shifts the peak to lower angles as compared to the as-grown sample. Meanwhile, no appreciable change in the full width at half maximum (FWHM) is noticed as a result of annealing. The SIMS analysis (bottom right inset in Fig. 1) of the as-grown and annealed (at $\left.750{ }^{\circ} \mathrm{C}\right) \mathrm{ZnO}: \mathrm{Er}(1 \%)$ samples confirms uniform Er distribution in these samples. Rutherford backscattering spectroscopy and channeling were also performed on the $\mathrm{ZnO}: \mathrm{Er}$ $(1 \%)$ sample, and the Er substitutional fraction $\left(f_{S}\right)$ was estimated to be 0.57 and 0.25 for the as-grown and annealed samples, respectively.

Table I lists the carrier concentration ( $n$ ) of the $\mathrm{ZnO}$ samples doped with $1 \%$ and $2 \% \mathrm{Er}$ in the as-grown state and upon annealing at different temperatures. Samples with both the Er compositions show similar thermal evolution in the electron concentration. The electron concentrations are $\mathrm{n} \sim 10^{20} \mathrm{~cm}^{-3}$ for the as-grown samples. After annealing at $750^{\circ} \mathrm{C}, n$ abruptly dropped to $\sim 10^{17} \mathrm{~cm}^{-3}$ and $\sim 10^{19} \mathrm{~cm}^{-3}$ for the $1 \%$ and $2 \%$ Er-doped samples, respectively.

Low temperature (10K) PL was performed to study the optical properties of the $\mathrm{ZnO}: \mathrm{Er}$ films. Figure 2, shows the PL spectra of the ZnO:Er (1\%) films annealed at different temperatures. Annealing introduced the intra- $4 \mathrm{f}$-shell transition emission of Er, namely, ${ }^{4} \mathrm{~F}_{9 / 2} \rightarrow{ }^{4} \mathrm{I}_{15 / 2}$ and ${ }^{4} \mathrm{~S}_{3 / 2} \rightarrow{ }^{4} \mathrm{I}_{15 / 2}$. Its intensity reached the maximum at the annealing temperature of $750^{\circ} \mathrm{C}$. Further increasing the annealing temperature to $850^{\circ} \mathrm{C}$ leads to the drop in the emission intensity. Similar

TABLE I. Carrier concentration (n) of the $\mathrm{ZnO}: \mathrm{Er}(1 \%$ and $2 \%$ ) samples treated with different post-growth annealing temperatures.

\begin{tabular}{lcccc}
\hline \hline Composition & $\begin{array}{c}\text { As grown } \\
\left(\mathrm{cm}^{-3}\right)\end{array}$ & $\begin{array}{c}650^{\circ} \mathrm{C} \\
\left(\mathrm{cm}^{-3}\right)\end{array}$ & $\begin{array}{l}750^{\circ} \mathrm{C} \\
\left(\mathrm{cm}^{-3}\right)\end{array}$ & $\begin{array}{l}850^{\circ} \mathrm{C} \\
\left(\mathrm{cm}^{-3}\right)\end{array}$ \\
\hline $1 \%$ & $-1.46 \times 10^{20}$ & $-1.03 \times 10^{20}$ & $-7.00 \times 10^{17}$ & $-4.72 \times 10^{18}$ \\
$2 \%$ & $-3.47 \times 10^{20}$ & $-1.96 \times 10^{20}$ & $-7.30 \times 10^{19}$ & $-4.12 \times 10^{18}$ \\
\hline \hline
\end{tabular}




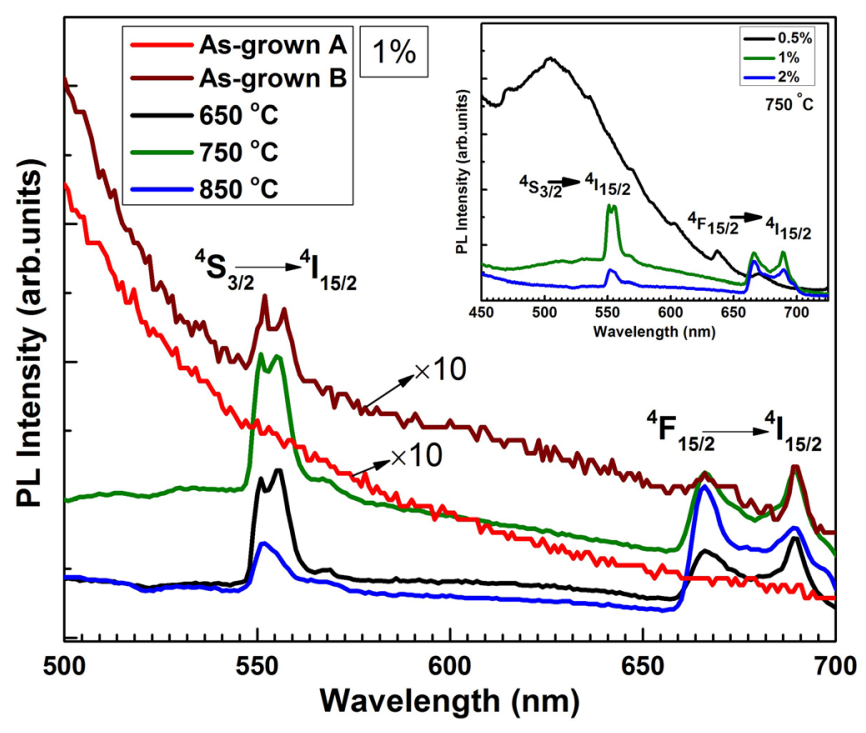

FIG. 2. The low temperature PL spectra $(10 \mathrm{~K})$ of the $\mathrm{ZnO}: \mathrm{Er}(1 \%)$ films treated at different post-growth annealing temperatures. As-grown A and As-grown B are the as-grown samples grown at the substrate temperature of $600^{\circ} \mathrm{C}$ and $750^{\circ} \mathrm{C}$, respectively. The annealing study was then carried out with the samples grown with the substrate temperature of $600^{\circ} \mathrm{C}$. The inset shows the low temperature $(10 \mathrm{~K}) \mathrm{PL}$ spectrum of the $750^{\circ} \mathrm{C}$ annealed $\mathrm{ZnO}:$ Er films having various Er contents.

annealing behavior was also observed for the $\mathrm{ZnO}: \mathrm{Er}(2 \%)$ samples. The inset of Fig. 2 shows the low temperature PL spectra of the $\mathrm{ZnO}$ :Er samples annealed at $750{ }^{\circ} \mathrm{C}$ with the Er compositions of $0.5 \%, 1 \%$, and $2 \%$. No intra-shell emissions were observed in the $\mathrm{ZnO}: \mathrm{Er}(0.5 \%)$ sample series regardless of the annealing. Notably, the maximum intrashell emission intensity is seen in the $1 \%$ Er-doped sample, while its intensity weakens in the $2 \%$ Er-doped sample. This decrease may be attributed to the segregation of Er into the grain boundaries. ${ }^{18} \mathrm{We}$ have also carried out study on the optical active $\mathrm{ZnO}: \operatorname{Er}(1 \%)$ samples (i.e., upon annealing at $750{ }^{\circ} \mathrm{C}$ ) grown with different oxygen pressures to reveal the dependence of the intensities of the intra-shell transition emissions on the oxygen pressure during growth. No such significant or systematic changes on the emission intensity were found. It was also found that the as-grown $\mathrm{ZnO}: \mathrm{Er}(1 \%)$ sample could also be optically active for the intra-4f-shell transitions while grown at the higher substrate temperature of $750{ }^{\circ} \mathrm{C}$ in $1.5 \mathrm{~Pa}$ of oxygen partial pressure (see the spectra in Fig. 2). However, the emission intensity was 20 times weaker than that from the $750^{\circ} \mathrm{C}$ annealed sample fabricated at the substrate temperature of $600^{\circ} \mathrm{C}$.

In order to further understand, we have carried out studies of hydrogen plasma treatment (HPT) and high resolution XPS on the $\mathrm{ZnO}: \mathrm{Er}(1 \%)$ samples. To study the effects of hydrogen plasma treatment (HPT) and the post-HPT annealing on the intra-transition emission of Er, room temperature hydrogen plasma treatment (HPT) was performed on the $\mathrm{ZnO}: \mathrm{Er}(1 \%)$ samples annealed at $750^{\circ} \mathrm{C}$. Figure 3 shows the low temperature PL spectra of (1) the $\mathrm{ZnO}: \mathrm{Er}$ sample annealed at $750^{\circ} \mathrm{C}$ (denoted by sample $750^{\circ} \mathrm{C}$ ); (2) the sample $750^{\circ} \mathrm{C}$ subjected to the HPT (denoted by sample $750^{\circ} \mathrm{C}+\mathrm{HPT}$ ); and (3) the sample $750{ }^{\circ} \mathrm{C}+\mathrm{HPT}$ annealed at $750^{\circ} \mathrm{C}$ again (denoted by sample $750^{\circ} \mathrm{C}+\mathrm{HPT}+750^{\circ} \mathrm{C}$ ). As expected, sample $750^{\circ} \mathrm{C}$ exhibits

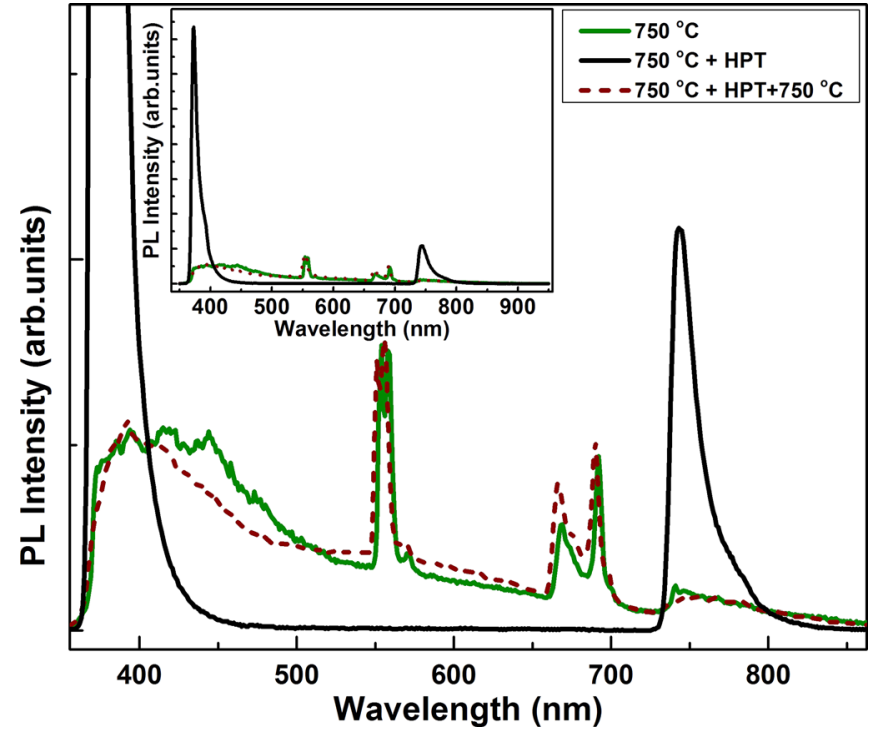

FIG. 3. The $10 \mathrm{~K}$ PL spectra of (i) $\mathrm{ZnO}: \mathrm{Er}(1 \%)$ as-annealed at $750{ }^{\circ} \mathrm{C}$; (ii) $\mathrm{H}$-plasma treated after annealing at $750{ }^{\circ} \mathrm{C}$; and (iii) sample obtained in (ii) annealed at $750^{\circ} \mathrm{C}$ again. The inset shows the full-scale spectra.

the characteristic Er intra-transition emission. After the HPT process (i.e., sample $750{ }^{\circ} \mathrm{C}+\mathrm{HPT}$ ), a strong narrow band emission line at $\sim 370 \mathrm{~nm}$ and another emission line at $\sim 750 \mathrm{~nm}$ (Ref. 19) appear and the Er intra-transition emission disappears. The inset of Fig. 3 shows the same PL spectra in full scale. In a previous PL measurement of $\mathrm{H}$ plasma treated un-doped $\mathrm{ZnO}$ films in the wavelength range of $350 \mathrm{~nm}$ to $500 \mathrm{~nm}$, the similar enhancement of the UV emission at $\sim 370 \mathrm{~nm}$ wavelength (>20 times) was also observed. As shown in Fig. 3, the PL spectrum of the sample $750^{\circ} \mathrm{C}+\mathrm{HPT}$ $+750^{\circ} \mathrm{C}$ (i.e., the sample post-HPT annealed at $750{ }^{\circ} \mathrm{C}$ ) shows that the Er intra-transition emission is recovered by the post-HPT annealing at $750{ }^{\circ} \mathrm{C}$. As HPT at room temperature usually involves surface modification to the samples, ${ }^{20}$ it is reasonable to suggest that the optically active $\mathrm{Er}$ responsible for the intra-4f-shell transition emission resides in the vicinity of the surface in the Er-doped $\mathrm{ZnO}$ film.

Another experiment was performed to elucidate the location of the Er optical active center. A very thin film of undoped $\mathrm{ZnO}(10 \mathrm{~nm})$ was grown on half of the surface of the ZnO:Er (1\%) sample annealed at $750^{\circ} \mathrm{C}$ (see Fig. 4). PL measurements were conducted on the sample surface covered and uncovered with the undoped $\mathrm{ZnO}$ thin film. As expected, ${ }^{4} \mathrm{~S}_{3 / 2} \rightarrow{ }^{4} \mathrm{I}_{15 / 2}$ and ${ }^{4} \mathrm{~F}_{9 / 2} \rightarrow{ }^{4} \mathrm{I}_{15 / 2}$ intra-shell emissions were observed in the PL spectrum taken on the uncovered area (as shown in Fig. 4). However, the intra-shell emissions were not found in the PL spectrum of the undoped $\mathrm{ZnO}$ covered region (as shown in Fig. 4). We have also carried out optical transmittance measurements on $\mathrm{ZnO}$ :Er samples with and without the $10 \mathrm{~nm}$ undoped $\mathrm{ZnO}$ thin film coverage. Their optical transmittance spectra presented in Fig. 4 showed that the transmittances of the samples with and without the undoped $\mathrm{ZnO}$ coverage did not have a difference more than the fraction of $10 \%$ in the wavelength range of the Er intra-shell ${ }^{4} \mathrm{~S}_{3 / 2}$ $\rightarrow{ }^{4} \mathrm{I}_{15 / 2}$ and ${ }^{4} \mathrm{~F}_{9 / 2} \rightarrow{ }^{4} \mathrm{I}_{15 / 2}$ emissions. As according to the light attenuation decay $\sim \exp (-\mathrm{x} \alpha)$ and the value of the light attenuation coefficient $\alpha\left(2.2 \times 10^{-12} \mathrm{~m}^{-1}\right)$ obtained from a 


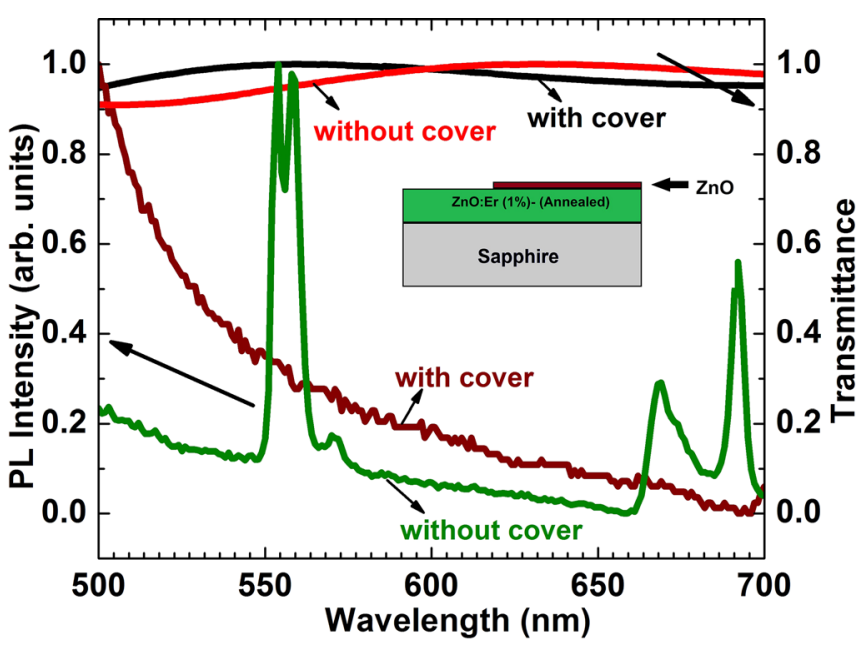

FIG. 4. PL signal and optical transmittance with and without the added $\mathrm{ZnO}$ top layer. The schematic of the fabricated sample is also shown in the inset.

transmittance measurement on our undoped $\mathrm{ZnO}$ film, $10 \mathrm{~nm}$ of the thin undoped $\mathrm{ZnO}$ film would expect to attenuate $6.0 \%$ of light intensity in the wavelength around intra-shell emissions. Thus, the complete diminishment of the intra-shell transition emission from the covered region was not expected. One possible explanation is that the added $10 \mathrm{~nm}$ undoped $\mathrm{ZnO}$ thin film changed the microstructure of the optical active Er center residing on the $\mathrm{ZnO}$ :Er film surface, thus deactivating its optical activity.

A high resolution XPS Er-4d peak study was performed on the optically inactive (as-grown) $\mathrm{ZnO}$ :Er sample, the optical active $\mathrm{ZnO}: \mathrm{Er}$ sample annealed at $750^{\circ} \mathrm{C}$ (i.e., sample $750{ }^{\circ} \mathrm{C}$ ), and the optical inactive hydrogen plasma treated sample (i.e., sample $750{ }^{\circ} \mathrm{C}+\mathrm{HPT}$ ). On each of the samples, XPS measurements were carried out on the surface and also in the bulk at a depth of $\sim 20 \mathrm{~nm}$ below the surface, and the results are shown in Fig. 5. For the optical inactive as-grown sample, the Er-4d XPS spectra show peaks at the binding energy (BE) of $\sim 169 \mathrm{eV}$, regardless of the spectra taken on the surface or in the bulk. The BE of $169 \mathrm{eV}$ is the characteristic of the $\mathrm{Er}^{3+}$ state. ${ }^{21}$ After the annealing at $750{ }^{\circ} \mathrm{C}$ which makes the sample optically active, the Er-4d XPS spectrum taken in the bulk remains at $\sim 169 \mathrm{eV}$, but that taken on the surface shifts to a larger $\mathrm{BE}$ of $\sim 171 \mathrm{eV}$. For sample $750{ }^{\circ} \mathrm{C}+\mathrm{HPT}$ with the optical activeness deactivated by the HPT, the Er-4d XPS spectra taken on the surface and in the bulk show the same peaks at $\sim 169 \mathrm{eV}$. As in the previous paragraph, the HPT study shows that the optical activity is activated by annealing the $\mathrm{ZnO}:$ Er sample at $750{ }^{\circ} \mathrm{C}$, and the optically active Er center only resides on the surface. The $\mathrm{BE}$ of Er-4d in the metal is lower than that of $\mathrm{Er}_{2} \mathrm{O}_{3}$ [167.25 eV (Ref. 22) and $168.5 \mathrm{eV}$ (Refs. 23 and 24), respectively]. For the as-grown and annealed $\mathrm{ZnO}$ :Er samples, only the XPS spectrum of the annealed sample taken on the surface shows a shift up of $\mathrm{BE}$ to $\sim 171 \mathrm{eV}$, and the remaining all shows a $\mathrm{BE}$ of $\sim 169 \mathrm{eV}$. This implies that the Er residing on the surface (but not in the bulk) has higher coordination with the oxygen after annealing at $750{ }^{\circ} \mathrm{C}$, which is compatible with understanding that the surficial Er changes to the six-fold coordination with oxygen, thus leading to the optical

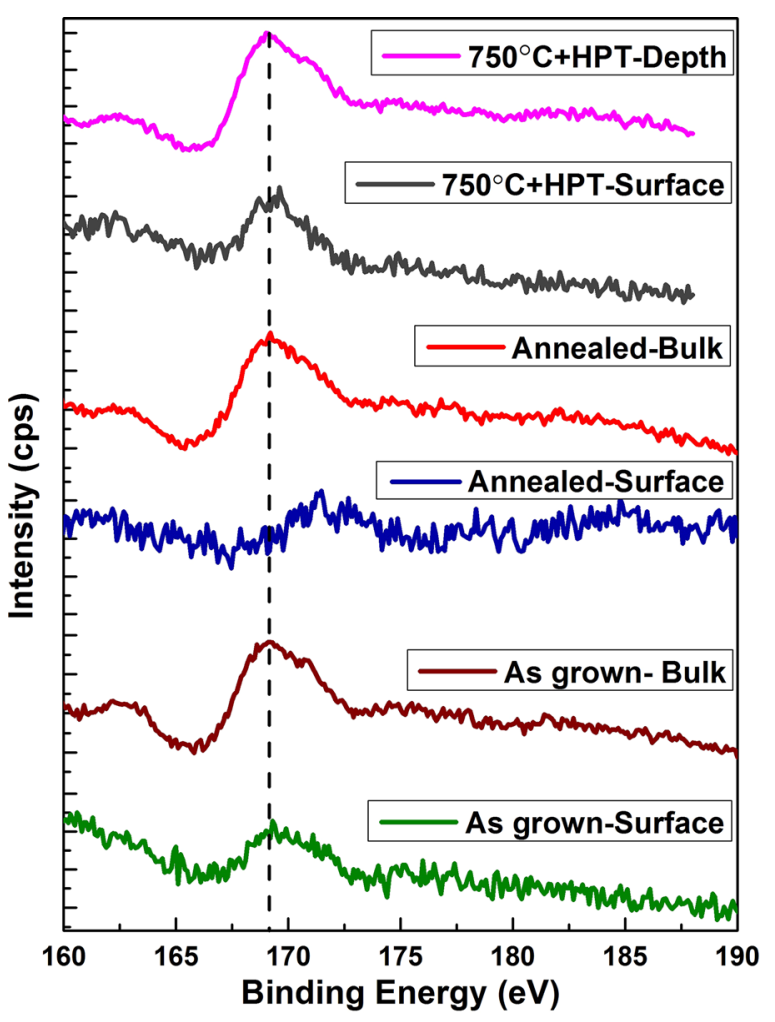

FIG. 5. High resolution XPS spectra of the Er-4d peak for the as-grown $\mathrm{ZnO}: \mathrm{Er}(1 \%)$ sample; the $\mathrm{ZnO}: \mathrm{Er}(1 \%)$ sample annealed at $750{ }^{\circ} \mathrm{C}$; and the $\mathrm{ZnO}: \mathrm{Er}(1 \%)$ sample annealed at $750^{\circ} \mathrm{C}$ followed by HPT.

activity of the surficial Er. Spectacularly enough, the blue shift of the Er-4d peak restores back to $\sim 169 \mathrm{eV}$ in the sample subjected for HPT, which also correlates well with the loss of its optical activity after the HPT. The XPS spectra of the optically inactive films and active films taken at the surface and in the bulk showed perfect correlation that the optical active centers are associated with higher coordination with oxygen and were only in the vicinity of the film surface.

\section{CONCLUSION}

In summary, Er-doped $\mathrm{ZnO}$ films were fabricated by the PLD method. Annealing of the optically inactive as-grown samples at $750{ }^{\circ} \mathrm{C}$ in $\mathrm{Ar}$ induced the optical emission originating from the Er-related intra-4f-shell transition ${ }^{4} \mathrm{~F}_{9 / 2} \rightarrow{ }^{4} \mathrm{I}_{15 / 2}$ and ${ }^{4} \mathrm{~S}_{3 / 2} \rightarrow{ }^{4} \mathrm{I}_{15 / 2}$ as seen in the PL spectra. The results of the plasma treatment study, the XPS study, and the PL spectra of the $\mathrm{ZnO}:$ Er film covered with the addition of the very thin undoped $\mathrm{ZnO}$ film showed that the optical activation was associated with the higher coordination of oxygen to Er as induced by the thermal annealing, but occurring only for atoms localized in the vicinity of the surface.

\section{ACKNOWLEDGMENTS}

This work was financially supported by the HKSAR RGC GRF (Project No. 17302115) and Seed Fund for Basic Research HKU (201411159019). MIDas and SiNoraPV administrated by the research council of Norway are also acknowledged for their partial financial support. 
${ }^{1}$ S. Lanzerstorfer, L. Palmetshofer, W. Jantsch, and J. Stimmer, Appl. Phys. Lett. 72, 809 (1998).

${ }^{2}$ S. Coffa, G. Franzo, F. Priolo, A. Pacellii, and A. Lacaita, Appl. Phys. Lett. 73, 93 (1998).

${ }^{3}$ X. Zhao, S. Komuro, H. Isshiki, Y. Aoyagi, and T. Sugano, Appl. Phys. Lett. 74, 120 (1999).

${ }^{4}$ Y. Yang, Y. Li, L. Xiang, X. Ma, and D. Yang, Appl. Phys. Lett. 102, 181111 (2013).

${ }^{5}$ P. G. Kik, M. J. de Dood, K. Kikoin, and A. Polman, Appl. Phys. Lett. 70, 1721 (1997).

${ }^{6}$ K. Takahei and A. Tagushi, J. Appl. Phys. 74, 1979 (1993).

${ }^{7}$ F. Priolo, C. Franzo, S. Coffa, A. Polman, S. Libertino, R. Barklie, and D. Carey, J. Appl. Phys. 78, 3874 (1995).

${ }^{8}$ H. Ennen, G. Pomrenke, A. Axmann, K. Eisele, W. Haydl, and J. Schneider, Appl. Phys. Lett. 46, 381 (1985).

${ }^{9}$ S. Coffa, G. Franzo, F. Priolo, A. Polman, and R. Serna, Phys. Rev. B 49, 16313 (1994).

${ }^{10}$ J. Palm, F. Gan, B. Zhang, J. Michel, and L. C. Kimerling, Phys. Rev. B 54, 17603 (1996).

${ }^{11}$ P. N. Favennec, H. L'Haridon, M. Salvi, D. Moutonnet, and T. Le Guillou, Electron. Lett. 25, 718 (1989).

${ }^{12}$ J. Wang, M. J. Zhou, S. K. Hark, Q. Li, D. Tang, M. W. Chu, and C. H. Chen, Appl. Phys. Lett. 89, 221917 (2006)

${ }^{13}$ A. K. Pradhan, L. Douglas, H. Mustafa, R. Mundle, D. Hunter, and C. E. Bonner, Appl. Phys. Lett. 90, 072108 (2007).
${ }^{14}$ Y. Terai, K. Yamaoka, T. Yamaguchi, and Y. Fujiwara, J. Vac. Sci. Technol., B 27, 2248 (2009).

${ }^{15}$ T. Fukudome, A. Kaminaka, H. Isshiki, R. Saito, S. Yugo, and T. Kimura, Nucl. Instrum. Methods Phys. Res., Sect. B 206, 287 (2003).

${ }^{16}$ S. Komuro, T. Katsumata, T. Morikawa, X. Zhao, H. Isshiki, and Y. Aoyagi, Appl. Phys. Lett. 76, 3935 (2000).

${ }^{17}$ M. Ishii, S. Komuro, T. Morikawa, and Y. Aoyagi, J. Appl. Phys. 89, 3679 (2001).

${ }^{18}$ R. P. Casero, A. G. Llorente, O. P. Y. Moll, W. Seiler, R. M. Defourneau, D. Defourneau, E. Millon, J. Perriere, P. Goldner, and B. Viana, J. Appl. Phys. 97, 054905 (2005).

${ }^{19}$ J. J. Dong, X. W. Zhang, J. B. You, P. F. Cai, Z. G. Yin, Q. An, X. B. Ma, P. Jin, Z. G. Wang, and P. K. Chu, ACS Appl. Mater. Interfaces 2(6), 1780 (2010).

${ }^{20}$ H. R. Kim, G. H. Lee, and D. H. Kim, J. Phys. D: Appl. Phys. 44, 185203 (2011).

${ }^{21}$ C. Mao, W. Li, F. Wu, Y. Dou, L. Fang, H. Ruan, and C. Kong, J. Mater. Sci.: Mater. Electron. 26, 8732 (2015).

${ }^{22}$ C. J. Powell, J. Electron Spectrosc. Relat. Phenom. 185, 1 (2012).

${ }^{23}$ M. Losurdo, M. Giangregorio, G. Bruno, D. Yang, E. A. Irene, A. A. Suvorova, and M. Saunders, Appl. Phys. Lett. 91, 091914 (2007).

${ }^{24}$ F. H. Chen, J. L. Her, Y. H. Shao, Y. H. Matsuda, and T. M. Pan, Nanoscale Res. Lett. 8, 18 (2013). 